\section{A166 DISEASE AMELIORATION IN THE K/BXN MOUSE MODEL OF SPONTANEOUS CHRONIC ARTHRITIS AFTER CD8 T CELL DEPLETION}

BRRaposo, A M Água-Doce, J A Pereira da Silva, LGraça, M M Souto-Carneiro Centro de Neurociências e Biologia Celular, University of Coimbra, Portugal

10.1136/ard.2010.129668c

CD8 T cells are part of the T cell pool infiltrating the rheumatoid synovial membrane. Moreover, CD8 T cells have been linked to the formation of synovial ectopic germinal centres in rheumatoid arthritis (RA), and they produce proinflammatory cytokines. Hence, CD8 T cells appear to be intimately involved in initiating and maintaining the chronic inflammation in the RA synovium. Nevertheless, studies on animal models of arthritis have not been able to clearly identify the role of $\mathrm{CD} 8$ in inflammatory synovitis. Using the $\mathrm{K} / \mathrm{BxN}$ mouse model of spontaneous chronic arthritis which shares many similarities with human RA, the authors have studied the potential of CD8 $\mathrm{T}$ cell depletion with monoclonal antibodies ( $\mathrm{mAbs}$ ) in stopping and reversing the progression of experimental arthritis. Mice treated with anti-CD8 had an improvement in the arthritis score only 5 days after the $\mathrm{mAb}$ injection. Disease signs improved on average $60-70 \%$ compared with the control group. Recovery of the CD8 T cell population was associated with an increase in the arthritis score. Mice subject to total thymectomy permanently kept a very low arthritis score. Histological analysis showed an absence of inflammatory infiltrate in the anti-CD8 treated animals and signs of novel cartilage synthesis. One month after anti-CD8 injection the serological levels of proinflammatory cytokines (tumour necrosis factor $\alpha$, interferon $\gamma$, interleukin 2 (IL2), IL5) fell significantly $(p<0.05)$ from baseline values. No changes were observed in the serum levels of the disease-related antiglucose-6-phosphate-isomerase antibodies. However, the levels of circulating CXCR4 expressing $\mathrm{B}$ cells and CD4 $\mathrm{T}$ cells normalised after therapy. Taken together, these results indicate that activated effector CD8 T cells synthesise proinflammatory cytokines in the arthritic joint, thus playing a pivotal role in maintaining chronic synovitis in the $\mathrm{K} / \mathrm{BxN}$ model of experimental chronic arthritis. The pathogenic role of CD8 T cells in experimental chronic arthritis can be reversed by blockade and/or depletion of CD8 T cells.

This work was supported by the Marie Curie IEF LIF-025885 and the EULAR Young Investigator Award to MMS-C. 